DOI: $10.20472 / E F C .2018 .009 .012$

\title{
TANAPOL RATTANASAMAKARN
}

Faculty of Economics, Chiang Mai University, Thailand

ROENGCHAI TANSUCHAT

Faculty of Economics, Chiang Mai University, Thailand

\section{REALIZED VOLATILITY IN AGRICULTURAL COMMODITIES FUTURES}

\begin{abstract}
:
The objectives of this paper are to construct the efficient frontier and optimum portfolio of agricultural commodity futures, and to evaluate financial risk by Value at Risk. We evaluated alternative volatility forecasting and computed daily Value at Risk (VaR) based on Realized Volatility approach and ARFIMA - FIGARCH model. The intraday trade data of three agricultural commodity futures prices, namely corn, wheat and soybean traded in the Chicago Board of Trade (CBOT) with three different frequencies namely 1 minute, 5 minutes and 15 minutes, were collected from Bloomberg database. The complete data set covered the period from November 2015 to December 2016. The empirical results showed that the calculated realized volatility from Realized Covariance Measure (Andersen et al. 2003) of corn, wheat and soybean futures returns have the long memory feature for every frequency based on R/S test and GPH test. The simulated returns from ARFIMA FIGARCH are applied to construct the efficient frontier and optimum portfolio. The optimum portfolio suggested investing more than half in corn followed by soybean and wheat, respectively.
\end{abstract}

\section{Keywords:}

Realized Volatility, Agriculture futures, Long-memory, Portfolio Optimization

JEL Classification: C58, G11, G32 


\section{Introduction}

Commodity is a basic good, either material or product, traded commercially and can be used interchangeably with other commodities of the same type. Commodities are most often used as inputs in the production of other goods or services. The quality of a given commodity may differ slightly, but it is essentially uniform across producers. When they are traded on an exchange, commodities must also meet specified minimum standards for the type for examples crude oil, copper, natural gas, wheat, corn, rubber, etc. (World Bank, 2017).

The price of a commodity depends on the demand-supply from the producers and the buyers. Investors or speculators are more likely to buy commodities, resulting in higher volatility in commodity prices. Commodities also attract investors, commodity traders and speculators in terms of trade for implementation, speculation and hedging.

These factors all contribute to volatility in commodity prices particularly those of agricultural commodities which are also attributable to such internal factors as seasonality, weather vagaries, and natural disasters.

\section{Table 1. Nominal price indexes}

\begin{tabular}{|c|c|c|c|c|c|}
\hline \multirow{2}{*}{} & \multicolumn{5}{|c|}{ Price Indexes (2010=100) } \\
\cline { 2 - 6 } & $\mathbf{2 0 1 4}$ & $\mathbf{2 0 1 5}$ & $\mathbf{2 0 1 6}$ & $\mathbf{2 0 1 7}$ & $\mathbf{2 0 1 8}$ \\
\hline Energy & 118 & 65 & 55 & 68 & 71 \\
\hline Non-energy & 97 & 82 & 80 & 84 & 85 \\
\hline Agriculture & 103 & 89 & 89 & 89 & 90 \\
\hline Beverage & 102 & 94 & 91 & 83 & 84 \\
\hline Food & 107 & 91 & 92 & 92 & 93 \\
\hline Oils and meals & 109 & 85 & 90 & 89 & 91 \\
\hline Grains & 104 & 89 & 82 & 82 & 83 \\
\hline Other food & 108 & 100 & 105 & 106 & 106 \\
\hline Raw Materials & 92 & 83 & 80 & 82 & 83 \\
\hline Fertilizers & 100 & 95 & 75 & 72 & 72 \\
\hline Metals and Minerals & 85 & 67 & 63 & 77 & 76 \\
\hline
\end{tabular}

Source: World Bank, 2017.

Mostly, the buying and selling of commodities will be made through futures markets in the form of futures contracts. Futures market is a channel for investors and speculators to make profit and implement hedging. Agricultural commodity price volatility poses a risk called "commodity risk", which is the risk of commodity price fluctuations. Therefore, those who are exposed to this type of risk directly are commodity producers and users of the commodity as a non-dispensable input such as mining operation's owners, oil producers, car manufacturers, airlines, food manufacturers, jewelers, gold shops, etc. Commodity risk will directly affect earnings, profit or loss, especially if the commodity price is volatile.

Risk management has become a more common focus since the 1970s, especially among organizations with inclination toward risk-aversion. Risk management tools have been developed extensively, but the most popular one is Value at Risk (VaR) because $\mathrm{VaR}$ can analyze the value of the risk or damage the most concrete, say the amount of 
money lost, and is designed to be easy to use. The global financial market has begun to fluctuate more, resulting in increased demand for risk management measures.

In 2003, Andersen et al. analyzed and forecast realized volatility using high frequency data (Intraday data) and compared to low frequency data (Daily data). They found realized volatility calculated from high frequency is more accurate than that from low frequency (Andersen et al, 2003). Subsequently, in 2006 Chen compared realized volatility analysis using high frequency data and low frequency data. The results show that high frequency data can analyze the realized volatility better than low frequency data (Chen, Z. \& et al, 2006). In 2008, Degiannakis applied ARFIMAX and ARFIMAXTARCH to estimate the realized volatility (Degiannakis, S. \& et al, 2008). Then in 2011, Andersen et al introduced the concept of market microstructure noise for explaining realized volatility (Andersen, T. \& et al, 2011). And in 2016, Huang and Sharma studied the realized volatility and tested long-memory property in stock market through GARCH model (Huang, Z. \& et al, 2016 and Sharma, P., 2016). From the previous literature review, it was found that the use of high frequency data to calculate the realized volatility is more accurate than the use of low frequency data.

After extensive researches into realized volatility and the use of high frequency data, several researchers have brought the results to the fore. Thomakos et al. in 2003 conducted a study of realized volatility in futures markets using high frequency data and tested the long-memory property and they found that the commodity futures in the futures market have a long-memory moving behavior (Thomakos et al, 2003). Later in 2004, a long-memory test in agricultural commodities revealed that agricultural commodities have long-memory property (Jin et al, 2004). In 2005, Dehn et al also performed a volatility analysis in agricultural commodities using realized volatility model (Dehn et al, 2005). Then in 2012, Tansuchat et al. investigated long- memory property in agricultural futures markets using low frequency data which showed that agricultural futures had long-memory property (Tansuchat et al, 2012). In addition to the agricultural type, other commodities have been examined by realized volatility approach for example in the work by Wang et al that used high frequency data to analyze the realized volatility and the relationship between raw crude oil and natural gas futures prices (Wang et al, 2008).

In addition, many researchers have employed high frequency data to analyze the value at risk (Intraday VaR) such as Dionne, Shao in 2009 and Louzis in 2014 (Dionne et al., 2009, Shao et al., 2009 and Louzis et al., 2014), Aloui et al. in 2010 on analysis of energy value in energy products (Aloui et al., 2010), and Tian et al in 2017 that dealt with value at risk in agricultural commodities futures using high frequency data and HAR models (Tian et al., 2017). 


\section{Econometric Model}

\subsection{Realized Volatility}

We model realized variance as in the works of Andersen et al. $(2003,2007)$. The log price is assumed to follow a continuous time jump diffusion semi-martingale process:

$$
d p(t)=\mu(t) d t+\sigma(t) d W(t)+\kappa(t) d q(t) \quad, 0 \leq t \leq T,
$$

where $p(t)$ is log price, $\mu(t)$ is continuous and locally bounded variation process, $W(t)$ is a standard Brownian motion, $\sigma(t)$ is strictly positive stochastic volatility process independent from $W(t), \kappa$ is a jump size and $q$ is a counting process with a value of 1 when there is a jump and 0 otherwise (Jajuga 2001 and Laurent 2010).

The quadratic variation for cumulative return process is as follows (Andersen et al. 2007):

$$
[r, r]_{t}=\int_{t-1}^{t} \sigma^{2}(s) d s+\sum_{t-1<s \leq t} \kappa^{2}(s)
$$

The integral $\int_{t-1}^{t} \sigma^{2}(s) d W(s)$ is called integrated variance, whereas the second part of the sum is describing the jump process.

In discretely sampled returns with $\Delta$ standing for the time that lasts between consecutive returns and $r(t) \equiv p(t)-p(t-\Delta)$, realized variance $R V_{t}(\Delta)$ is calculated by the summation of squared intraday returns that are observed with given frequency:

$$
R V_{t}(\Delta)=\sum_{n=1}^{1 / \Delta} r_{t, n}^{2}
$$

As the sampling frequency of the return series increases,

$$
R V_{t}(\Delta)(\Delta)-B V_{t}(\Delta) \rightarrow \sum_{t-1<s \leq t} \kappa^{2}(s)
$$

In the absence of jumps, realized variance will be a consistent estimator of integrated variance. This result is fundamental for modelling and forecasting realized variance (Andersen et al. 2003). However, as jumps are quite common in financial returns series, realized variance is not a robust estimator of integrated variance. Barndorff-Nielsen and Shephard (2004) introduced another measure called bipower variation which is a robust estimate of integrated variance. These two, realized variance and bipower variation $B V_{t}(\Delta)$ allow therefore estimating the jump component in the price process:

$$
R V_{t}(\Delta)-B V_{t}(\Delta) \rightarrow \sum_{t-1<s \leq t} \kappa^{2}(s)
$$

In order to prevent the estimates of squared returns from being negative, BarndorffNielsen and Shephard (2004) truncated the measurement of jumps $J$ at zero:

$$
J_{t}=\max \left[R V_{t}(\Delta)-B V_{t}(\Delta), 0\right]
$$




\subsection{Long - memory property}

The estimated daily $\mathrm{RV}$ from med $R V_{t}$ is checked for long memory property by two long memory tests, namely R/S test (Hurst) and GPH test (Geweke and Porter-Hudak). The $\mathrm{R} / \mathrm{S}$ test of range over standard deviation test is defined as:

$$
Q_{T}=\frac{1}{S_{T}}\left[\max _{1 \leqslant k \leqslant T} \sum_{j=1}^{k}\left(y_{j}-\bar{y}\right)-\min _{1 \leq k \leq T} \sum_{j=1}^{k}\left(y_{j}-\bar{y}\right)\right],
$$

where $\bar{y}=1 / T \sum_{i=1}^{T} y_{j}$ and $s_{T}=\sqrt{1 / T \sum_{i=1}^{T}\left(y_{j}-\bar{y}\right)}$. The null hypothesis of R/S test is no long term dependence. Alternatively, the GPH test, given the fractionally integrated process of $y$ the spectral density $f(\omega)=\left[4 \sin ^{2}\left(\frac{\omega}{2}\right)\right]^{-d} f_{u}(\omega)$ where is $\omega$ the Fourier frequency, and $f_{u}(\omega)$ is the spectral density corresponding to $u_{t}$. The $d$ can be estimated by least square of the following regression:

$$
\ln f\left(\omega_{j}\right)=\beta-d \ln \left[4 \sin ^{2}\left(\frac{\omega_{j}}{2}\right)\right]+e_{j}
$$

For $j=1,2, \ldots, n_{f}(T)$. The distribution of $\hat{d}$ with the large sample if $n_{f}(T)=T^{\alpha}, 0<\alpha<1$ is normal distribution, $d \square N\left(d, \frac{\pi^{2}}{6 \sum_{j=1}^{n}\left(U_{j}-\bar{U}\right)^{2}}\right)$ with $U_{j}=\ln \left[4 \sin ^{2}\left(\frac{\omega_{j}}{2}\right)\right]$, and $\bar{U}$ is the sample mean of $U_{j}, j=1, \ldots, n_{f}$. The null hypothesis of no long memory $d=0$ is tested by traditional statistic.

\subsection{ARFIMA - FIGRCH}

In estimating an ARIMA model, the researchers choose the integer order of differencing $\mathrm{d}$ to ensure that the resulting series $(1-L)^{d} y_{t}$ is a stationary process. As unit root tests often lack the power to distinguish between a truly nonstationary $(I(1))$ series and a stationary series embodying a structural break or shift, time series are often firstdifferenced if they fail to pass unit root test. Many time series exhibit too much longrange dependence to be classified as $I(0)$ but are not $I(1)$. The ARFIMA model is designed to represent these series. This problem is exacerbated by reliance on DickeyFuller style tests, including the improved Elliott, et al. (1996) test, which have I(1) as the null hypothesis and $I(0)$ as the alternative. For that reason, it is also a good idea to employ a test with the alternative null hypothesis of stationarity $(I(0))$ such as the Kwiatkowski-Phillips-Schmidt-Shin test to see if its verdict agrees with that of the Dickey-Fuller style test.

The model of an autoregressive fractionally integrated moving average process of a time series of order $(p: d: q)$, denoted by $\operatorname{ARFIMA}(p: d: q)$ with mean $\mu$, may be written using operator notation as

$$
\phi(L)(1-L)^{d}\left(y_{t}-\mu\right)=\Theta(L) \varepsilon_{t}, \varepsilon_{t}: \text { i.i.d. }\left(0, \sigma_{\varepsilon}^{2}\right),
$$


where $L$ is the backward-shift operator, $\phi(L)=1-\phi_{1} L-\ldots-\phi_{p} L^{p}, \quad \Theta(L)=1+v_{1} L+\ldots+v_{q} L^{q}$ and $(1-\mathrm{L})^{d}$ is the fractional differencing operator defined by

$$
(1-L)^{d}=\sum_{k=0}^{\infty} \frac{\Gamma(k-d) L^{k}}{\Gamma(-d) \Gamma(k+1)}
$$

with $\Gamma(\cdot)$ denoting the gamma (generalized factorial) function. The parameter $d$ is allowed to assume any real value.

\subsection{Value at Risk (VaR)}

In order to analyze the risk, we calculate the empirical VaR and ES of an equally weighted portfolio with 3 assets. The equations are as follows:

$$
M I N \quad E S=E\left[r \mid r \leq r_{\alpha}\right]
$$

subject to

$$
\begin{gathered}
r=w\left[r_{(1, t+1)}+r_{(2, t+1)}+r_{(3, t+1)}+r_{(4, t+1)}\right] \\
w_{1}=w_{2}=w_{3}=w_{4}=\frac{1}{4} \\
0 \leq w_{i} \leq 1, i=1,2,3,4
\end{gathered}
$$

where $r_{\alpha}$ is the lower $\alpha$ - quintile and $r_{i, t+1}$ is the return on individual asset at time $t+1$

\subsection{Portfolio Optimization}

From the above section, we can estimate the VaR and ES (or CVaR) of equally weighted portfolio. In this part, we use the Monte Carlo simulation with estimated multivariate $t$ copula to generate $n$ sample size. The optimal portfolios weights of the selected assets then are constructed under minimization of expected shortfalls with respect to maximization of returns, which can be given by:

$$
\min E S=E\left[r \mid r \leq r_{\alpha}\right]
$$

subject to

$$
\begin{gathered}
r=w_{1} r_{(1, t+1)}+w_{2} r_{(1, t+2)}+w_{3} r_{(1, t+3)}+w_{4} r_{(1, t+4)} \\
w_{1}+w_{2}+w_{3}+w_{4}=1 \\
0 \leq w_{i} \leq 1, i=1,2,3,4
\end{gathered}
$$

where $r_{\alpha}$ is the lower $\alpha$ - quintile and $r_{i, t+1}$ is the return on individual asset at time $t+1$

\section{Data}

The high frequency data at 1, 5, and 10 minutes of the futures price of 3 agricultures -namely wheat, corn and soybean traded in the Chicago Board of Trade were collected from Bloomberg database, from Financial Investment Center (FIC), Faculty of Economics, Chiang Mai University. The study period started from November 11, 2015 to December 8, 2016 with the total of $560,160,112,032$ and 37,344 tick data, respectively. 


\section{Empirical Results}

In this section, the empirical results from the present study are presented. First, the Augmented DickeyFuller (ADF) test is used to explore the existence of unit roots in individual returns series. Based on the ADF test results, the large negative values in all cases indicate rejection of the null hypothesis at the $1 \%$ level. Next, we test long memory property in realized volatility of agricultural futures by two long memory tests, namely R/S test (Hurst) and GPH test (Geweke and Porter-Hudak). The realized volatility of all agricultural commodity futures has a long - memory property.

\section{Figture 1 Daily RV of corn futures with 1, 5 and 15 Minutes by Realized covariance measure}
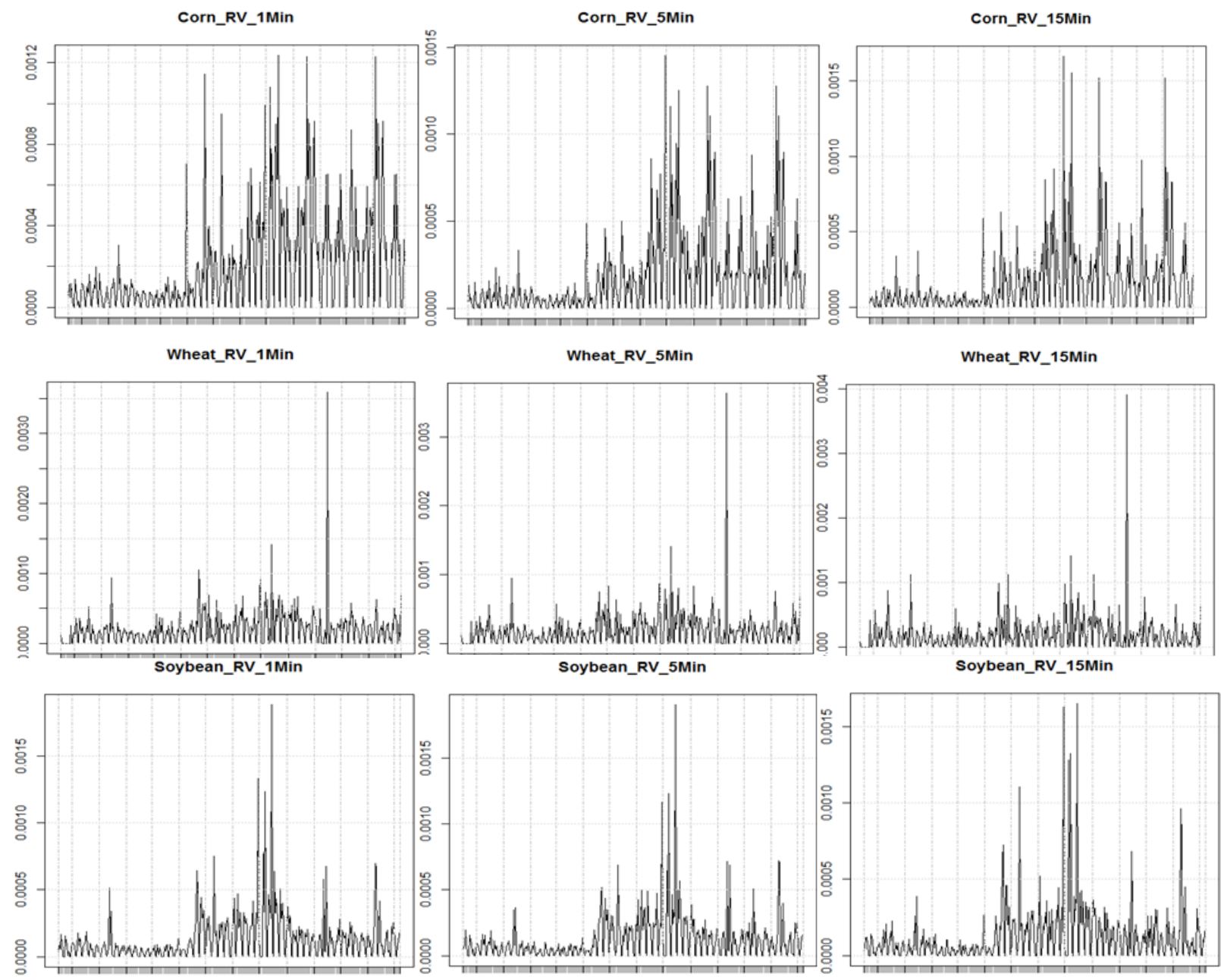

Source: Calculation

The results of ARFIMA - FIGARCH model estimation for corn, wheat and soybean with 1,5 and 15 minutes (the ARFIMA (p,d,q) - FIGARCH $(p, d, q)$ model for agricultural commodity futures at $p=1,2,3$ and $q=1,2,3$ and FIGARCH model $p, q=1)$. The estimates of ARFIMA - FIGARCH model for corn with 1,5 and 15 minutes to estimate $d$ parameters in ARFIMA - FIGARCH. From the results, all frequencies are statistically significant, and lie between 0 and 1. Next, the estimates of ARFIMA - FIGARCH model for wheat with 1,5 and 15 minutes to estimate d parameters in ARFIMA - FIGARCH. From the results, all frequencies are statistically significant, and lie between 0 and 1 . 
Lastly, the estimates of ARFIMA - FIGARCH model for soybean with 1, 5 and 15 minutes to estimate d parameters in ARFIMA - FIGARCH. From the results all frequencies are statistically significant, and lie between 0 and 1 .

Table 2. Estimated ARFIMA - FIGARCH model for corn

\begin{tabular}{|c|c|c|c|c|c|c|}
\hline \multicolumn{4}{|c|}{ Model } & \multirow{3}{*}{ Frequency } & \multirow{3}{*}{$d$-ARFIMA } & \multirow{3}{*}{ d-FIGARCH } \\
\hline \multicolumn{2}{|c|}{ ARFIMA } & \multicolumn{2}{|c|}{ FIGARCH } & & & \\
\hline$p$ & 9 & $p$ & $q$ & & & \\
\hline 1 & 1 & 1 & 1 & \multirow{4}{*}{1 minute } & -0.39776 & 0.99548 \\
\hline 1 & 2 & 1 & 1 & & -0.05075 & -0.30754 \\
\hline 2 & 1 & 1 & 1 & & -1.16986 & 0.61251 \\
\hline 2 & 2 & 1 & 1 & & -1.34566 & 0.44105 \\
\hline 1 & 1 & 1 & 1 & \multirow{4}{*}{5 minutes } & -0.07125 & 0.11486 \\
\hline 1 & 2 & 1 & 1 & & -0.31233 & 0.90809 \\
\hline 2 & 1 & 1 & 1 & & -1.21594 & 0.20319 \\
\hline 2 & 2 & 1 & 1 & & -0.19851 & 1.09931 \\
\hline 1 & 1 & 1 & 1 & \multirow{4}{*}{15 minutes } & 0.62645 & 0.63532 \\
\hline 1 & 2 & 1 & 1 & & -0.22312 & 1.22133 \\
\hline 2 & 1 & 1 & 1 & & -1.34012 & 0.45682 \\
\hline 2 & 2 & 1 & 1 & & 0.66512 & 0.63572 \\
\hline
\end{tabular}

Source: Calculation

The results of ARFIMA - FIGARCH model estimation for corn, wheat and soybean with 1,5 and 15 minutes (the ARFIMA $(p, d, q)-\operatorname{FIGARCH}(p, d, q)$ model for agricultural commodity futures at $p=1,2,3$ and $q=1,2,3$ and FIGARCH model $p, q=1$ ). The estimates of ARFIMA - FIGARCH model for corn with 1,5 and 15 minutes to estimate d parameters in ARFIMA - FIGARCH. From the results, all frequencies are statistically significant, and lie between 0 and 1 .

Table 3. Estimated ARFIMA - FIGARCH model for wheat

\begin{tabular}{|c|c|c|c|c|c|c|}
\hline \multicolumn{4}{|c|}{ Model } & \multirow{3}{*}{ Frequency } & \multirow{3}{*}{$d$-ARFIMA } & \multirow{3}{*}{$d-F I G A R C H$} \\
\hline \multicolumn{2}{|c|}{ ARFIMA } & \multicolumn{2}{|c|}{ FIGARCH } & & & \\
\hline$p$ & 9 & $p$ & 9 & & & \\
\hline 1 & 1 & 1 & 1 & \multirow{4}{*}{1 minute } & -0.98159 & 0.48637 \\
\hline 1 & 2 & 1 & 1 & & -0.79205 & 0.59901 \\
\hline 2 & 1 & 1 & 1 & & -1.07788 & 0.33558 \\
\hline 2 & 2 & 1 & 1 & & -0.13029 & 0.15722 \\
\hline 1 & 1 & 1 & 1 & \multirow{4}{*}{5 minutes } & -0.23847 & 0.74475 \\
\hline 1 & 2 & 1 & 1 & & $0.48255^{\star *}$ & 0.15292 \\
\hline 2 & 1 & 1 & 1 & & -0.05951 & 0.12026 \\
\hline 2 & 2 & 1 & 1 & & $0.21907^{* *}$ & 0.72335 \\
\hline 1 & 1 & 1 & 1 & \multirow{4}{*}{15 minutes } & -1.00724 & -0.091 \\
\hline 1 & 2 & 1 & 1 & & -0.83587 & 0.8764 \\
\hline 2 & 1 & 1 & 1 & & -1.09288 & 0.4321 \\
\hline 2 & 2 & 1 & 1 & & 0.38471 & 0.3326 \\
\hline
\end{tabular}

Source: Calculation

Next, the estimates of ARFIMA - FIGARCH model for wheat with 1,5 and 15 minutes to estimate d parameters in ARFIMA - FIGARCH. From the results, all frequencies are statistically significant, and lie between 0 and 1. Lastly, the estimates of ARFIMA FIGARCH model for soybean with 1,5 and 15 minutes to estimate $d$ parameters in ARFIMA - FIGARCH. From the results all frequencies are statistically significant, and lie between 0 and 1. 
Table 4. Estimated ARFIMA - FIGARCH model for soybean

\begin{tabular}{|c|c|c|c|c|c|c|}
\hline \multicolumn{4}{|c|}{ Model } & \multirow{3}{*}{ Frequency } & \multirow{3}{*}{$d$-ARFIMA } & \multirow{3}{*}{$d-F I G A R C H$} \\
\hline \multicolumn{2}{|c|}{ ARFIMA } & \multicolumn{2}{|c|}{ FIGARCH } & & & \\
\hline$p$ & $q$ & $p$ & 9 & & & \\
\hline 1 & 1 & 1 & 1 & \multirow{4}{*}{1 minute } & $0.03110^{\star *}$ & -0.06715 \\
\hline 1 & 2 & 1 & 1 & & 0.84488 & 0.78165 \\
\hline 2 & 1 & 1 & 1 & & -1.18625 & 0.00645 \\
\hline 2 & 2 & 1 & 1 & & -1.14191 & 0.61517 \\
\hline 1 & 1 & 1 & 1 & \multirow{4}{*}{5 minutes } & -0.23463 & -0.94184 \\
\hline 1 & 2 & 1 & 1 & & -0.82148 & 0.64777 \\
\hline 2 & 1 & 1 & 1 & & $0.18226^{* *}$ & 0.35197 \\
\hline 2 & 2 & 1 & 1 & & -0.00792 & 0.90203 \\
\hline 1 & 1 & 1 & 1 & \multirow{4}{*}{15 minutes } & -1.03899 & -1.02557 \\
\hline 1 & 2 & 1 & 1 & & 0.64321 & 0.74152 \\
\hline 2 & 1 & 1 & 1 & & -0.18263 & -0.65142 \\
\hline 2 & 2 & 1 & 1 & & -0.34252 & 0.43621 \\
\hline
\end{tabular}

Source: Calculation

Table 5. Estimated ARFIMA - FIGARCH model for corn

\begin{tabular}{|c|c|c|c|c|c|c|c|c|}
\hline \multicolumn{6}{|c|}{ Model } & \multirow{3}{*}{ Frequency } & \multirow{3}{*}{$A I C$} & \multirow{3}{*}{ Log-likelihood } \\
\hline \multicolumn{3}{|c|}{ ARFIMA } & \multicolumn{3}{|c|}{ FIGARCH } & & & \\
\hline$p$ & $d$ & 9 & $p$ & $d$ & 9 & & & \\
\hline 1 & -0.39776 & 1 & 1 & 0.99548 & 1 & \multirow{4}{*}{1 minute } & -13.0926 & 793.558 \\
\hline 1 & -0.05075 & 2 & 1 & -0.30754 & 1 & & -13.0736 & 793.413 \\
\hline 2 & -1.16986 & 1 & 1 & 0.61251 & 1 & & -13.2406 & 803.436 \\
\hline 2 & -1.34566 & 2 & 1 & 0.44105 & 1 & & -13.3265 & 809.589 \\
\hline 1 & -0.07125 & 1 & 1 & 0.11486 & 1 & \multirow{4}{*}{5 minutes } & -13.0612 & 793.669 \\
\hline 1 & -0.31233 & 2 & 1 & 0.90809 & 1 & & -13.4803 & 819.819 \\
\hline 2 & -1.21594 & 1 & 1 & 0.20319 & 1 & & -13.6409 & 828.451 \\
\hline 2 & -0.19851 & 2 & 1 & 1.09931 & 1 & & -13.391 & 814.459 \\
\hline 1 & 0.62645 & 1 & 1 & 0.63532 & 1 & \multirow{4}{*}{15 minutes } & -13.4284 & 817.707 \\
\hline 1 & -0.22312 & 2 & 1 & 1.22133 & 1 & & -13.3427 & 798.104 \\
\hline 2 & -1.34012 & 1 & 1 & 0.45682 & 1 & & -13.3424 & 796.207 \\
\hline 2 & 0.66512 & 2 & 1 & 0.63572 & 1 & & -13.8472 & 799.503 \\
\hline
\end{tabular}

Source: Calculation

Tables $2-4$ present information for Model Selection by Akaike information criterion (AIC). Table 9 shows for corn, according to the lowest AIC, the best model with 1 minute is ARFIMA $(1,-0.05075,2)-$ FIGARCH $(1,-0.30754,1)$, and the best models with 5 and 15 minutes are ARFIMA $(1,-0.07125,1)-\operatorname{FIGARCH}(1,0.11486,1)$ and ARFIMA $(2,-1.34012,1)-$ FIGARCH $(1,0.45682,1)$, respectively.

For wheat (Table 3), the best model with 1 minute is ARFIMA $(2,-0.13029,2)-$ FIGARCH $(1,0.15722,1)$ and the preferred ones with 5 and 15 minutes are ARFIMA $(1,-0.23847,1)-$ FIGARCH $(1,0.74475,1)$ and ARFIMA $(1,-0.83587,2)-$ FIGARCH $(1,0.8764,1)$, respectively.

For soybean (Table 4), the best model with 1 minute is ARFIMA $(2,-1.14191,2)$ FIGARCH $(1,0.61517,1)$ and the best ones with 5 and 15 minutes are ARFIMA (1, - 
$0.23463,1)-\operatorname{FIGARCH}(1,-0.94184,1)$ and $\operatorname{ARFIMA}(1,0.64321,2)-\operatorname{FIGARCH}(1$, $0.74152,1)$, respectively.

Table 6. Estimated ARFIMA - FIGARCH model for wheat

\begin{tabular}{|c|c|c|c|c|c|c|c|c|}
\hline \multicolumn{6}{|c|}{ Model } & \multirow{3}{*}{ Frequency } & \multirow{3}{*}{$A I C$} & \multirow{3}{*}{$\begin{array}{c}\text { Log- } \\
\text { likelihood }\end{array}$} \\
\hline \multicolumn{3}{|c|}{ ARFIMA } & \multicolumn{3}{|c|}{ FIGARCH } & & & \\
\hline$p$ & $d$ & $q$ & $p$ & $d$ & 9 & & & \\
\hline 1 & -0.98159 & 1 & 1 & 0.48637 & 1 & \multirow{4}{*}{1 minute } & -13.178 & 798.682 \\
\hline 1 & -0.79205 & 2 & 1 & 0.59901 & 1 & & -13.2589 & 804.536 \\
\hline 2 & -1.07788 & 1 & 1 & 0.33558 & 1 & & -13.6308 & 826.849 \\
\hline 2 & -0.13029 & 2 & 1 & 0.15722 & 1 & & -13.0122 & 790.73 \\
\hline 1 & -0.23847 & 1 & 1 & 0.74475 & 1 & \multirow{4}{*}{5 minutes } & -13.1212 & 797.269 \\
\hline 1 & 0.48255 & 2 & 1 & 0.15292 & 1 & & -13.426 & 816.561 \\
\hline 2 & -0.05951 & 1 & 1 & 0.12026 & 1 & & -13.906 & 844.363 \\
\hline 2 & 0.21907 & 2 & 1 & 0.72335 & 1 & & -13.7728 & 837.367 \\
\hline 1 & -1.00724 & 1 & 1 & -0.091 & 1 & \multirow{4}{*}{15 minutes } & -13.2918 & 809.511 \\
\hline 1 & -0.83587 & 2 & 1 & 0.8764 & 1 & & -13.2406 & 803.436 \\
\hline 2 & -1.09288 & 1 & 1 & 0.4321 & 1 & & -13.3265 & 809.589 \\
\hline 2 & 0.38471 & 2 & 1 & 0.3326 & 1 & & -13.6409 & 793.669 \\
\hline
\end{tabular}

Source: Calculation

Table 7. Estimated ARFIMA - FIGARCH model for soybean

\begin{tabular}{|c|c|c|c|c|c|c|c|c|}
\hline \multicolumn{6}{|c|}{ Model } & \multirow{3}{*}{ Frequency } & \multirow{3}{*}{$A / C$} & \multirow{3}{*}{$\begin{array}{c}\text { Log- } \\
\text { likelihood }\end{array}$} \\
\hline \multicolumn{3}{|c|}{ ARFIMA } & \multicolumn{3}{|c|}{ FIGARCH } & & & \\
\hline$p$ & $d$ & $q$ & $p$ & $d$ & $q$ & & & \\
\hline 1 & $0.03110^{\star *}$ & 1 & 1 & -0.06715 & 1 & \multirow{4}{*}{1 minutes } & -13.1684 & 798.104 \\
\hline 1 & 0.84488 & 2 & 1 & 0.78165 & 1 & & -13.1201 & 796.207 \\
\hline 2 & -1.18625 & 1 & 1 & 0.00645 & 1 & & -13.1751 & 799.503 \\
\hline 2 & -1.14191 & 2 & 1 & 0.61517 & 1 & & -13.0572 & 793.434 \\
\hline 1 & -0.23463 & 1 & 1 & -0.94184 & 1 & \multirow{4}{*}{5 minutes } & -13.2842 & 807.05 \\
\hline 1 & -0.82148 & 2 & 1 & 0.64777 & 1 & & -13.339 & 811.341 \\
\hline 2 & $0.18226^{* \star}$ & 1 & 1 & 0.35197 & 1 & & -13.3687 & 812.124 \\
\hline 2 & -0.00792 & 2 & 1 & 0.90203 & 1 & & -13.5311 & 822.867 \\
\hline 1 & -1.03899 & 1 & 1 & -1.02557 & 1 & \multirow{4}{*}{15 minutes } & -13.2413 & 806.479 \\
\hline 1 & 0.64321 & 2 & 1 & 0.74152 & 1 & & -13.0122 & 798.682 \\
\hline 2 & -0.18263 & 1 & 1 & -0.65142 & 1 & & -13.1212 & 804.536 \\
\hline 2 & -0.34252 & 2 & 1 & 0.43621 & 1 & & -13.426 & 826.849 \\
\hline
\end{tabular}

Source: Calculation

Table 11. Value at Risk and Expected Shortfall

\begin{tabular}{|c|c|c|c|c|}
\hline Risk & Frequency & $\mathbf{1 \%}$ & $\mathbf{5 \%}$ & $\mathbf{1 0 \%}$ \\
\hline \multirow{3}{*}{ Value at Risk: VaR } & 1 Minute & $8.98 \%$ & $6.33 \%$ & $4.92 \%$ \\
\cline { 2 - 5 } & 5 Minutes & $8.99 \%$ & $6.44 \%$ & $5.04 \%$ \\
\cline { 2 - 5 } Expected shortfall: ES & 15 Minutes & $8.89 \%$ & $6.24 \%$ & $4.88 \%$ \\
\hline & 1 Minute & $10.46 \%$ & $7.95 \%$ & $6.75 \%$ \\
\cline { 2 - 5 } & 5 Minutes & $10.22 \%$ & $8.00 \%$ & $6.85 \%$ \\
\cline { 2 - 5 } & 15 Minutes & $9.98 \%$ & $7.83 \%$ & $6.67 \%$ \\
\hline
\end{tabular}

Source: Calculation

In this paper we focused on realized volatility and ARFIMA - FIGARCH model to calculate $\mathrm{VaR}$ and portfolio optimization in agricultural futures. The calculated $\mathrm{VaR}$ and ES at $1 \%, 5 \%$, and $10 \%$ of the equally weighted portfolio of three agricultural futures (corn, wheat, and soybean) are shown in Table 11. All estimated ES's are higher than VaR. In portfolio with 1 minute VaR and ES are $4.92 \%, 6.33 \%$ and $8.98 \%$ at $10 \%, 5 \%$ 
and $1 \%$ level; and $6.75 \%, 7.95 \%$ and $10.46 \%$ at $10 \%, 5 \%$ and $1 \%$ level, respectively. In portfolio with 5 minutes $\mathrm{VaR}$ and $\mathrm{ES}$ are $5.04 \%, 6.44 \%$ and $8.99 \%$ at $10 \%, 5 \%$ and $1 \%$; and $6.85 \%, 8 \%$ and $10.22 \%$ at $10 \%, 5 \%$ and $1 \%$ level, respectively. In portfolio with 15 minutes $\mathrm{VaR}$ and $\mathrm{ES}$ are $4.88 \%, 6.24 \%$ and $8.89 \%$ at $10 \%, 5 \%$ and $1 \%$; and $6.67 \%$, $7.83 \%$ and $9.98 \%$ at $10 \%, 5 \%$ and $1 \%$ level, respectively.

Table 12 shows the optimal investment proportion of agriculture portfolio with minimum risk (ES 5\%) with different frequency--namely 1 minute, 5 minutes and 15 minutes. The optimal portfolio was calculated by minimizing the portfolio risk under minimization of expected shortfall with respect to maximization of returns. The results show that most of the investment proportion is corn while wheat and soybean have little of the investment proportion. In portfolios with 5 minutes, there are negative returns; while in portfolios with 1 minute and 15 minutes, there are positive returns.

\section{Table 12. Portfolio Optimization}

\begin{tabular}{|c|c|c|c|c|c|c|c|c|c|c|c|c|}
\hline \multirow{2}{*}{ Portfolio } & \multicolumn{4}{|c|}{1 Minute } & \multicolumn{4}{|c|}{5 Minutes } & \multicolumn{4}{|c|}{15 Minutes } \\
\hline & Wheat & Corn & Soybean & Return & Wheat & Corn & Soybean & Return & Wheat & Corn & Soybean & Return \\
\hline 1 & 0.16 & 0.65 & 0.18 & 0.0007 & 0.22 & 0.54 & 0.24 & -0.0006 & 0.2 & 0.58 & 0.22 & 0.0005 \\
\hline 2 & 0.13 & 0.68 & 0.17 & 0.0007 & 0.2 & 0.56 & 0.24 & -0.0005 & 0.18 & 0.62 & 0.2 & 0.0005 \\
\hline 3 & 0.1 & 0.71 & 0.17 & 0.0007 & 0.17 & 0.58 & 0.25 & -0.0005 & 0.15 & 0.67 & 0.18 & 0.0005 \\
\hline 4 & 0.07 & 0.75 & 0.17 & 0.0007 & 0.15 & 0.6 & 0.25 & -0.0005 & 0.12 & 0.71 & 0.17 & 0.0006 \\
\hline 5 & 0.05 & 0.79 & 0.15 & 0.0008 & 0.12 & 0.63 & 0.25 & -0.0005 & 0.09 & 0.76 & 0.15 & 0.0006 \\
\hline 6 & 0.03 & 0.82 & 0.14 & 0.0008 & 0.09 & 0.65 & 0.25 & -0.0005 & 0.06 & 0.8 & 0.14 & 0.0006 \\
\hline 7 & 0 & 0.86 & 0.13 & 0.0008 & 0.07 & 0.67 & 0.26 & -0.0004 & 0.03 & 0.85 & 0.12 & 0.0006 \\
\hline 8 & 0 & 0.9 & 0.09 & 0.0008 & 0.04 & 0.7 & 0.26 & -0.0004 & 0.01 & 0.89 & 0.1 & 0.0006 \\
\hline 9 & 0 & 0.95 & 0.04 & 0.0008 & 0.02 & 0.72 & 0.26 & -0.0004 & 0 & 0.94 & 0.06 & 0.0006 \\
\hline 10 & 0 & 1 & 0 & 0.0009 & 0 & 1 & 0 & -0.0004 & 0 & 1 & 0 & 0.0007 \\
\hline
\end{tabular}

Source: Calculation

\section{Conclusion}

The growing importance of intraday activities such as the high-frequency and the algorithm trading in the financial market has motivated us to propose the realized volatility and ARFIMA-FIGARCH model approach for improving the portfolio optimization and VaR evaluation explicitly using intraday returns. Therefor this study, we applied concept long memory property, realized volatility high-frequency and to evaluate risk of agriculture future. This paper aims to construct the optimum portfolio from the most commonly traded agricultural commodity futures, namely corn, wheat and soybean with three different frequencies namely 1 minute, 5 minutes, and 15 minutes. The dataset starting from November 2015 to December 2016 covering 560,160 of tick data and totally 389 days were collected from Bloomberg database. In the first step, we calculated realized volatility of corn, wheat and soybean from Realized Covariance Measure (rCov) with the three different frequencies as stated above. We tested longmemory property by R/S test and GPH test and found that corn, wheat and soybean futures returns have the long memory feature for every frequency. In the next step, we estimated realized volatility and simulated returns by ARFIMA - FIGARCH. Finally, we constructed the optimum portfolio. From the results on optimum portfolio, it is suggested that investment be made more than half in corn followed by soybean and wheat, respectively. The estimated VaR and ES of portfolio in period $t+1$ at $1 \%, 5 \%$ and $10 \%$ level are $8.98 \%, 6.33 \%, 4.92 \%$ and $10.46 \%, 7.95 \%, 6.75 \%$ respectively. 


\section{Acknowledgements}

The authors wish to thank Mr. Woraphon Yamaka for code assistance, and the financial support from the Faculty of Economics, Chiang Mai University, Thailand.

\section{References}

Aloui, C.; and Mabrouk, S. (2010). Value-at-risk Estimations of Energy Commodities via Long-memory, Asymmetry and Fat-tailed GARCH Models. Energy Policy, 38(5), 2326-2339.

Andersen, T. G.; Bollerslev, T.; Diebold, F. X. and Labys, P. (2003). Modeling and Forecasting Realized Volatility. Econometrica, 71(2), 579-625.

Andersen, T. G.; Bollerslev, T. and Meddahi, N. (2011). Realized Volatility Forecasting and Market Microstructure Noise. Journal of Econometrics, 160(1), 220-234.

Chang, C. L.; McAleer, M. and Tansuchat, R. (2012). Modelling Long Memory Volatility in Agricultural Commodity Futures Returns. Annals of Financial Economics, 7(02), 1250010.

Chen, Z.; Daigler, R. T. and Parhizgari, A. M. (2006). Persistence of Volatility in Futures Markets. Journal of Futures Markets, 26(6), 571-594.

Dehn, J.; Gilbert, C. and Varangis, P. (2005). Agricultural Commodity Price Volatility. Managing Economic Volatility and Crises: A Practitioner's Guide, 137-85.

Dionne, G.; Duchesne, P. and Pacurar, M. (2009). Intraday Value at Risk (IVaR) using Tick-by-Tick Data with Application to the Toronto Stock Exchange. Journal of Empirical Finance, 16(5), 777-792.

Elliott, G.; Rothenberg, T. J. and Stock, J. H. (1996) Efficient Tests for an Autoregressive Unit Root. Econometrica, vol. 64(4), pages 813-836

Huang, Z.; Liu, H. and Wang, T. (2016). Modeling Long Memory Volatility Using Realized Measures of Volatility: A Realized HAR GARCH model. Economic Modelling, 52, 812-821.

Louzis, D. P.; Xanthopoulos-Sisinis, S. and Refenes, A. P. (2014). Realized Volatility Models and Alternative Value-at-Risk Prediction Strategies. Economic Modelling, 40, 101-116.

Manfredo, M. and Leuthold, R. (1998). Agricultural Applications of Value-at-Risk Analysis: A Perspective. Finance 9805002, EconWPA.

Shao, X. D.; Lian, Y. J. and Yin, L. Q. (2009). Forecasting Value-at-Risk Using High Frequency Data: The Realized Range Model. Global Finance Journal, 20(2), 128-136.

Sharma, P. (2016). Forecasting Stock Market Volatility Using Realized GARCH model: International Evidence. The Quarterly Review of Economics and Finance, 59, 222-230.

Thomakos, D. D., and Wang, T. (2003). Realized Volatility in the Futures Markets. Journal of Empirical Finance, 10(3), 321-353.

Tian, F.; Yang, K.; and Chen, L. (2017). Realized Volatility Forecasting of Agricultural Commodity Futures Using the HAR Model with Time-Varying Sparsity. International Journal of Forecasting, 33(1), 132152.

Tomek, W. G.; and Peterson, H. H. (2001). Risk Management in Agricultural Markets: A Review. Journal of Futures Markets, 21(10), 953-985.

Wang, T., Wu, J., and Yang, J. (2008). Realized Volatility and Correlation in Energy Futures Markets. Journal of Futures Markets, 28(10), 993-1011.

World Bank (2017). Commodity Market Outlook. The World Bank.

Yang, K.; Tian, F.; Chen, L. and Li, S. (2017). Realized Volatility Forecast of Agricultural Futures Using the HAR Models with Bagging and Combination Approaches. International Review of Economics \& Finance, 49, 276-291. 